\title{
Drug refractory epilepsy in brain damage: effect of dextromethorphan on EEG in four patients
}

\author{
B Schmitt, R Netzer, S Fanconi, P Baumann, E Boltshauser
}

\begin{abstract}
High doses of dextromethorphan (20-42 mg/kg/day) were given to four critically ill children with seizures and frequent epileptiform abnormalities in the EEG that were refractory to antiepileptic drugs. Their acute diseases (hypoxia, head trauma and hypoxia, neurodegenerative disease, hypoglycaemia) were thought to be due in part to $\mathrm{N}$-methyl-Daspartate (NMDA) receptor mediated processes. Treatment with dextromethorphan, an NMDA receptor antagonist, was started between 48 hours and 14 days after the critical incident. In three patients the EEG improved considerably within 48 hours and seizures ceased within 72 hours. In the patient with neurodegenerative disease the effect on the EEG was impressive, but the seizures were not controlled. Despite the improvement of the EEG the clinical outcome was poor in all children: three died in the critical period or due to the progressing disease; the patient with hypoglycaemia survived with severe neurological sequelae. Plasma concentrations of dextromethorphan varied between 74-1730 $\mathrm{ng} / \mathrm{ml}$ and its metabolite dextrorphan varied between 349-3790 $\mathrm{ng} / \mathrm{ml}$. In one patient corresponding concentrations in CSF were lower than those in plasma. The suppression of epileptic discharges by the doses of dextromethorphan given suggests that such doses are sufficient to block NMDA receptors.
\end{abstract}

(F Neurol Neurosurg Psychiatry 1994;57:333-339)

Dextromethorphan, a morphine derivative without affinity for opioid receptors, has been used as an antitussive for more than 30 years. Recently, the drug was shown to have anticonvulsant properties in several in vitro $^{1-3}$ and in vivo models of epilepsy. ${ }^{4-6}$ Dextromethorphan is a non-competitive antagonist of the N-methyl-D-aspartate (NMDA) receptor channel. ${ }^{78}$ The substance has also been shown to reduce voltagedependent calcium and sodium currents with lower potency. 89

Because NMDA receptors play an important part in the pathophysiological mechanisms of various neurological disorders, including epilepsy, ${ }^{10}$ NMDA receptor channel blockers (for example, MK-801, dextromethorphan, ketamine, imipramine, desipramine) may have beneficial effects in the treatment of seizures. ${ }^{11-13}$ Recently, we have shown that dextromethorphan (35 $\mathrm{mg} / \mathrm{kg} /$ day in four doses) resulted in the cessation of seizures and normalisation of the EEG in a patient with non-ketotic hyperglycinaemia. ${ }^{14}$ Withdrawal of dextromethorphan was followed by dramatic clinical deterioration with epileptic and high voltage slow activity in the EEG. The symptoms disappeared again when the drug treatment was resumed after 48 hours.

Dextromethorphan might therefore be a useful antiepileptic drug for other forms of epilepsy. Because of potential side effects at high doses, use of dextromethorphan must be restricted. In four patients on intensive care with a desperate clinical situation, dextromethorphan was the final option for treatment of drug refractory epilepsy. None of the patients showed a satisfactory clinical outcome, but in each of them dextromethorphan impressively improved the EEG. It is the aim of this paper to discuss (1) the effects of dextromethorphan on the EEG at various doses; (2) the dextromethorphan concentration in plasma and CSF, (3) the reasons for the unsatisfactory outcome; (4) possible side effects; and (5) potential improvements for future management.

Our results are of a preliminary character. In all patients the decision to initiate treatment with dextromethorphan was made by consensus of at least two involved physicians from different departments; parents were informed.

Patients and methods

Dextromethorphan hydrobromide (Bexin) was orally administered by tube in four doses daily. Concentrations of dextromethorphan and its active main metabolite dextrorphan were determined in blood and CSF by gas chromatography-mass spectrometry after treatment with $\beta$-glucuronidase and arylsulphatase. ${ }^{15}$ EEGs were recorded on a 16 or 21 channel standard machine. Electrode placement was according to the international 10-20 system, paper speed $30 \mathrm{~mm} / \mathrm{s}$, low pass filter 60 or $70 \mathrm{~Hz}$, time constant 0.3 seconds, and minimal recording time 30 minutes.

\section{CASE 1}

Case 1 was a seven-month-old child with a tetralogy of Fallot. After total surgical correction, cardiac arrest occurred and resuscitation was necessary. Forty eight hours later the 
Figure 1 Case 1 (A) 48 hours after cardiac arrest, focal epileptic discharges; (B) 12 hours after introduction of dextromethorphan, free of epilepsy, severe slowing background activity.

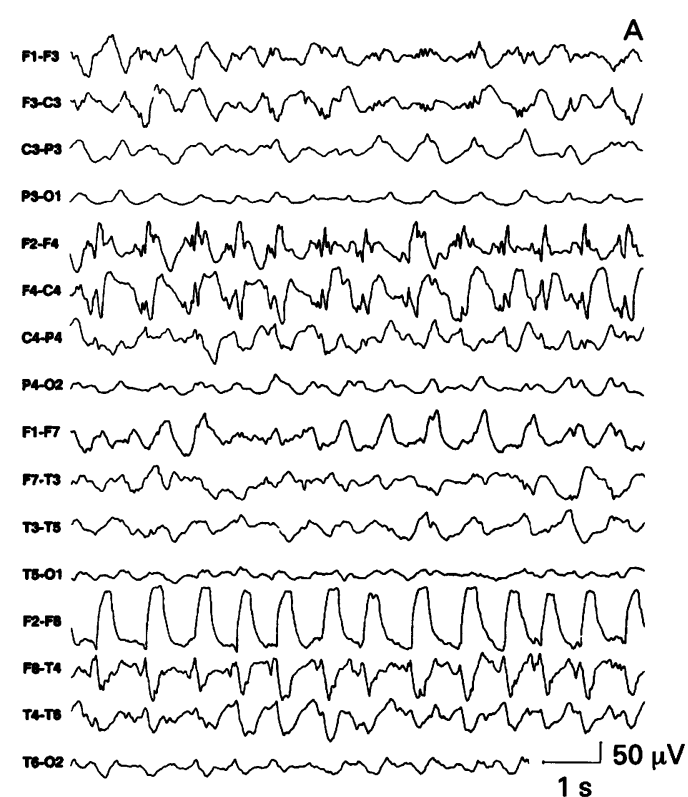

child had focal seizures that were refractory to phenobarbitone and diazepam. The EEG showed continuous focal epileptic discharges with varying localisations (fig 1a), which could be interrupted temporarily with clonazepam. Somatosensory evoked potentials (SEPs) showed a complete loss of cortical components. Brainstem acoustic evoked potentials were preserved. After treatment with dextromethorphan (30 $\mathrm{mg} / \mathrm{kg} /$ day) seizures stopped, the EEG, repeatedly recorded, was free of epileptic discharges, and background activity was slow (fig 1b). A CT scan two days later showed severe global ischaemic brain damage and life support measures were discontinued. Post mortem examination confirmed the extensive subacute anoxic encephalopathy.

CASE 2

A 14-year-old mentally retarded girl with poorly controlled epilepsy of unknown aetiology fell downstairs and suffered an impression fracture of the left temporal skull. Cardiorespiratory insufficiency required artificial ventilation. The initial EEGs (on days 2 and 3) revealed a "suppression-burst" pattern, which was replaced by rhythmical trains of delta waves over the frontal regions three days later. After extubation (11th day) the child was in a vegetative state. Three days later, under treatment with valproate and carbamazepine, she developed complex partial seizures coinciding with pronounced cyanosis. Phenobarbitone, phenytoin, and clonazepam were not efficient. Bilateral pneumonia and pleural effusion required artificial ventilation again. Refractory seizures and deterioration of the EEG (fig 2a) were taken as indications for treatment with dextromethorphan and this was given $(32 \mathrm{mg} /$ $\mathrm{kg} /$ day). Within hours seizures ceased and the multifocal spike and sharp waves disappeared (fig 2b). At intervals of 10-15 minutes low amplitude epileptic discharges over the region of the skull fracture occurred and remained

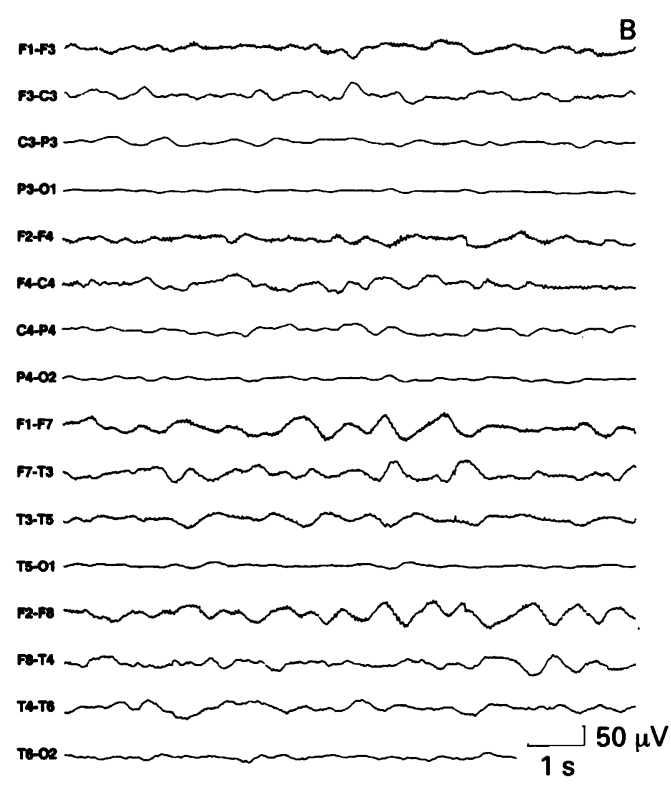

unaffected, although dextromethorphan was temporarily increased to $45 \mathrm{mg} / \mathrm{kg} /$ day. All other drugs, with the exception of clonazepam, were discontinued stepwise. In view of unexplained pronounced muscle hypertonia dextromethorphan was reduced to 22 $\mathrm{mg} / \mathrm{kg} /$ day - without influence on the muscle tone. Seven days later complex partial seizures (fig 2c) with pronounced cyanosis reoccurred and ceased again after increasing the dose to $35 \mathrm{mg} / \mathrm{kg} / \mathrm{day}$. After extubation the child persisted in a vegetative state and, due to pneumonia and pleural effusion, she again developed respiratory insufficiency. Because of the poor prognosis reintubation was avoided and the child died.

\section{CASE 3}

This patient had an elder brother with epilepsia partialis continua lasting more than four years, that started unexpectedly at the age of 5.5 years. He is now in a vegetative state.

The patient, a 4.5-year-old boy, was normal up to May 1992 when he, like his brother, unexpectedly had myoclonic seizures in the face and upper limbs. Seizures ceased after clonazepam and pentobarbitone and he fully recovered.

In August 1992, the boy again developed myoclonic jerks, which started in the right leg and foot, spread to the face, and coincided with increasing unconsciousness. Treatment with diazepam, phenytoin, phenobarbitone, chloral hydrate, thiopentone, and mannitol had no effect. Pentobarbitone interrupted the right hemiconvulsions, but continuous high amplitude slow spike or polyspike wave complexes persisted in the left hemisphere (fig 3a). A barbiturate coma with electrocerebral silence for 24 hours had no effect; therefore dextromethorphan was added (35 mg/kg/ day). After discontinuation of pentobarbitone the continuous right hemiconvulsions relapsed, occasionally coinciding with contracortical spike wave complexes (fig 3b). SEP amplitudes were attenuated in both 
Figure 2 Case 2, severe head trauma and hypoxia (A) 14th day, low voltage, multifocal spike, and sharp waves, intervening periods of inactivity; (B) 24 hours after introduction of dextromethorphan; $(C)$ seven days after reduction of dextromethorphan to 22 $\mathrm{mg} / \mathrm{kg} /$ day, complex partial seizures with cyanosis, series of rapid spikes.

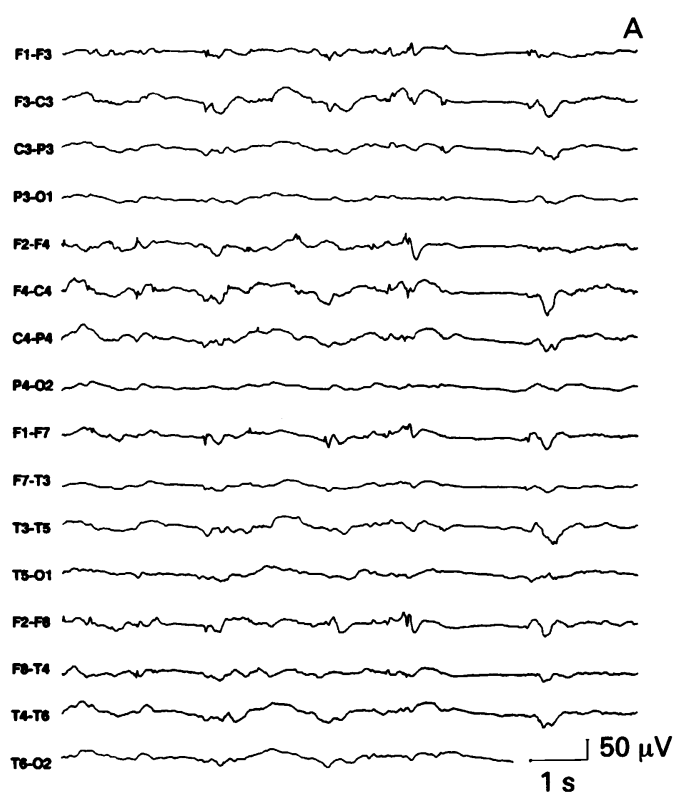

B

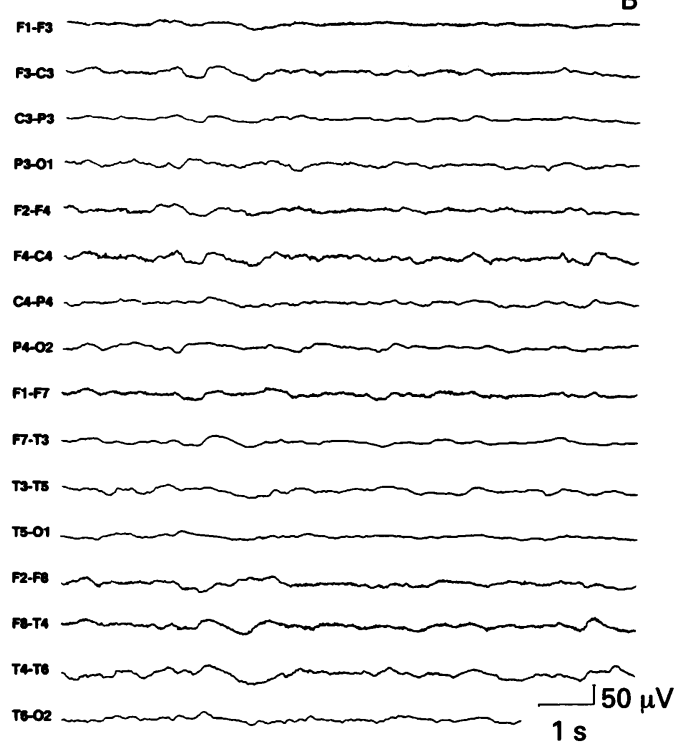

C

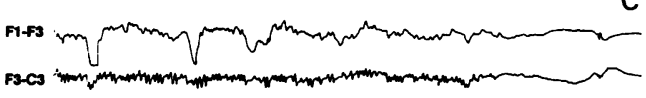

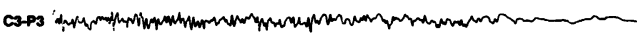

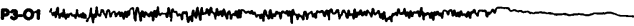

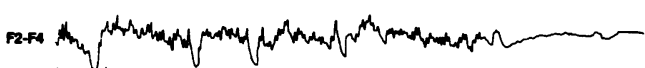

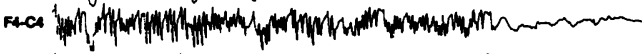

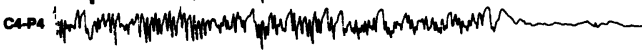

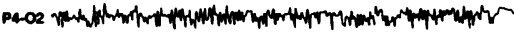

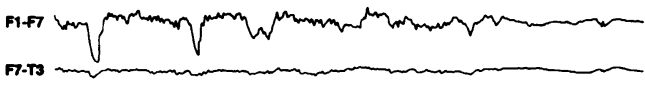

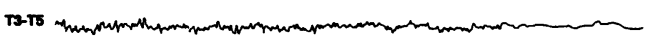

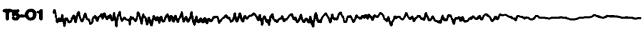

Pete

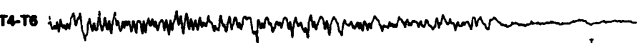

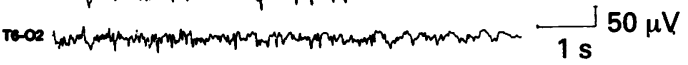

hemispheres. Assuming a lack of effect, dextromethorphan was gradually discontinued and clonazepam and valproate were given. The later course of the illness, complicated by a life-threattening pneumonia, showed frequent long lasting periods of myoclonic jerks, now on the left half of the body. After an interval of 17 days the EEG showed a continuous epileptic activity in the right hemisphere (fig 3c), independent of the myoclonic jerks. This pronounced deterioration in EEG suggested, retrospectively, a beneficial effect of dextromethorphan, and treatment with the drug was restarted. The EEG improved within days (fig $3 \mathrm{~d}$ ), but the myoclonic jerks persisted and the child remained in a vegetative state. Two weeks later, periods of respiratory insufficiency reoccurred. Dextromethorphan was reduced to $20 \mathrm{mg} / \mathrm{kg} /$ day, clonazepam was continued, and valproate discontinued. Although the EEG further improved (fig $3 \mathrm{e}$ ), the series of myoclonic jerks persisted, but, by contrast with his brother, no other seizures occurred. Due to the desperate situation medical care was reduced and dextromethorphan was discontinued stepwise. The child died 10 days after withdrawal of dextromethorphan. Postmortem evaluation of CSF revealed no detectable dextromethorphan or dextrorphan.

CASE 4

A two-year-old Japanese boy had a reduced food and fluid intake during a mild respiratory infection and after a long distance flight. In the morning he was found comatose with generalised convulsions and deepened breathing. On admission to hospital blood sugar of the febrile child was measured as nil. Intraveneous glucose was given immediately. The seizures, refractory to clonazepam and phenytoin, could be interrupted by phenobarbitone. Under treatment with phenytoin and phenobarbitone attacks of pronounced trismus, coinciding with apnoea, required artificial ventilation. A CT scan and assessment of CSF were normal and the EEG showed severe background slowing. Forty eight hours later thiopentone $(5 \mathrm{mg} / \mathrm{kg} / \mathrm{hour}$ ) was necessary to interrupt recurrent tonic-clonic seizures. Multifocal sharp waves, slow spike wave complexes, and long lasting epileptic discharges (fig 4a) persisted in the EEG and were not affected when clonazepam and pyridoxine were administered. Dextromethorphan ( $35 \mathrm{mg} / \mathrm{kg} /$ day) was added; 48 hours later epileptiform abnormalities were profoundly reduced and after 72 hours they were no longer present (fig 4b). Trismus and tonic seizures persisted for three days and disappeared after replacement of phenytoin by clonazepam. The MRI now showed cortical atrophy and demyelination. After 10 days, dextromethorphan was discontinued stepwise. The child, treated with phenobarbitone and clonazepam, remained seizure free, but increasing numbers of sharp waves reoccurred in the EEG. The child showed a very slow recovery and, up to now, severe neurological sequelae. 
Figure 3 Case 3, neurodegenerative disease (A) epilepsia partialis continua; (B) after barbiturate coma, dextromethorphan (25 mg/kg/day), jerks related cortical spike wave complexes over the left central region (EMG $1=$ right arm, EMG 2 = right thigh); (C) 17 days after discontinuation of dextromethorphan, myoclonic jerks, now on the left body half; (D) after reintroduction of dextromethorphan (35 $m g / k g / d a y) ;(E)$ five weeks later, treatment with clonazepam and dextromethorphan (20 $\mathrm{mg} / \mathrm{kg} /$ day)

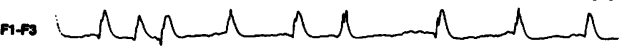

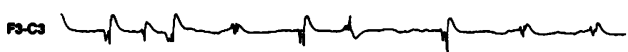
caps $\mathrm{rrm}_{\mathrm{rar}}$

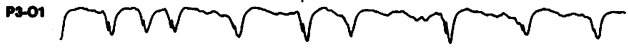

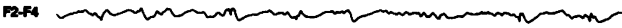

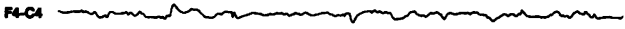

CAP4

Pa.02

F1-F

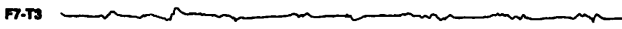

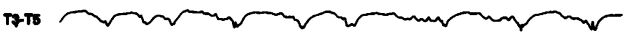



Pere

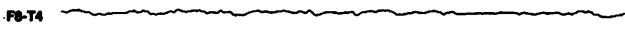

T4T0 $1 \mathrm{~s}$

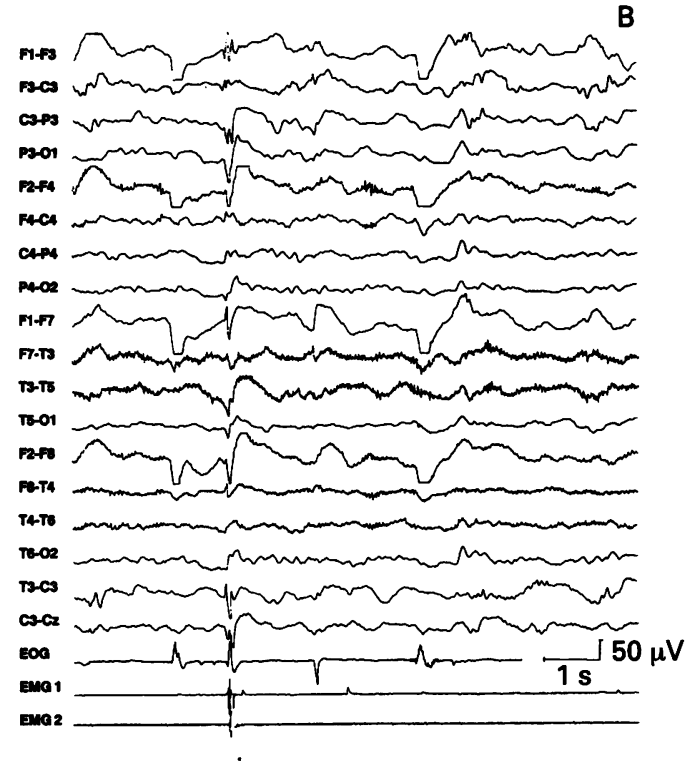
(1)

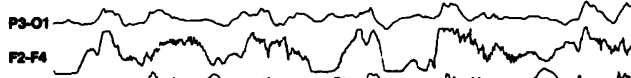
CaPA (1-7) 7.T3 T3-T5 20101 T4-TS

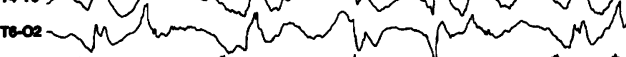
rocs, cace

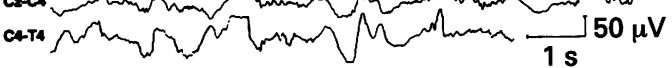

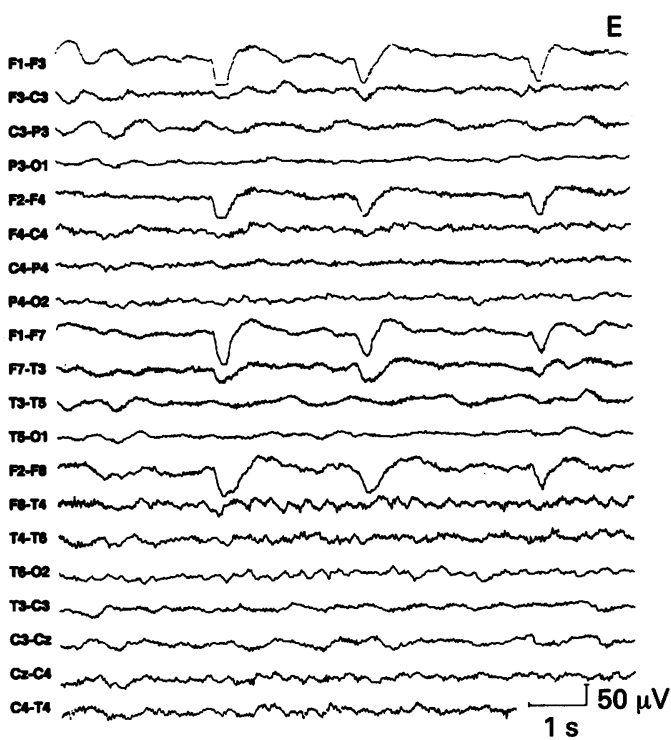

\section{Discussion}

EEG

The impressive effect of dextromethorphan on the EEG of the four patients supports the findings in our patient with non-ketotic hyperglycinaemia. ${ }^{14}$ Reduction or discontinuation of dextromethorphan was followed by the reoccurrence or increase of epileptiform abnormalities in the EEG (cases 2 and 4). Dextromethorphan, but not its metabolite dextrorphan, is believed to amplify the anticonvulsant effects of phenytoin. ${ }^{16}$ This effect is unlikely to play a part in our patients because (1) different drugs were used; (2) the effect of dextromethorphan persisted when antiepileptic drugs were discontinued; and (3) the patient with non-ketotic hyperglycinaemia was treated with dextromethorphan alone. ${ }^{14}$

Anticonvulsant properties of dextromethorphan have been described in various in vitro and in vivo models of epilepsy. ${ }^{4617-19}$ 
Figure 4 Case 4, after 5th day, drug refractory multifocal slow spike wave complexes; (B) 48 hours after addition of dextromethorphan (35 $\mathrm{mg} / \mathrm{kg} /$ day) to treatment severe hypoglycaemia $(A)$

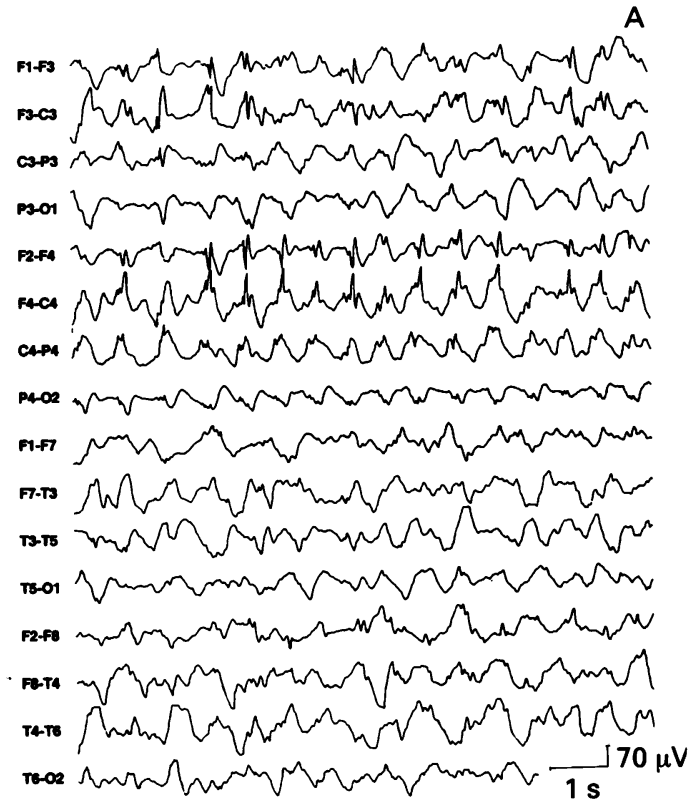

The underlying mechanism is believed to be a block of the NMDA receptor channel. This is also assumed for the main metabolite of dextromethorphan, dextrorphan. ${ }^{7-9}$ Overstimulation of the NMDA receptor seems to play a key part in brain damage in hypoxia (cases 1 and 2), severe head trauma (case 2), hypoglycaemia (case 4), and neurodegenerative diseases (case 3). ${ }^{20-23}$ Epilepsy in these patients may be induced by NMDA receptormediated processes. In animal studies of NMDA-induced convulsions, only NMDA receptor antagonists, and not conventional antiepileptic drugs, are effective. ${ }^{5}$ In seizures caused by other pathomechanisms, the NMDA receptor antagonists prevent epileptic brain damage even when they do not suppress electrographic seizures. ${ }^{24} 25$

The additional effect of dextromethorphan on voltage-gated calcium channels might also contribute to the anticonvulsant properties. Blocking calcium currents has been shown to have an anticonvulsant effect in in vitro ${ }^{26}$ and in vivo experiments. ${ }^{27}$ Much higher concentrations of dextromethorphan are necessary to inhibit the voltage-gated calcium channels than to block NMDA-induced currents. ${ }^{9}$

Clinical experiences with dextromethorphan were reported by Fisher et al. ${ }^{28}$ They gave dextromethorphan $(120 \mathrm{mg} /$ day $\approx 2$ $\mathrm{mg} / \mathrm{kg} /$ day) as add-on therapy to adults with intractable complex partial seizures, without

Table Concentrations of dextromethorphan (DM) and dextrorphan (DX)

\begin{tabular}{llllll}
\hline Case & $\begin{array}{l}\text { Dose } \\
(\mathrm{mg} / \mathrm{kg} / \text { day })\end{array}$ & $\begin{array}{l}\text { Hours after } \mathrm{DM} \\
\text { treatment }\end{array}$ & Source & $\begin{array}{l}\text { DM } \\
(\mathrm{ng} / \mathrm{ml})\end{array}$ & $\begin{array}{l}\text { DX } \\
(\mathrm{ng} / \mathrm{ml})\end{array}$ \\
\hline 1 & 28 & 20 & Plasma & 1730 & 2170 \\
2 & 22 & 2 & Plasma & 1050 & 1590 \\
3 & 35 & 6 & Plasma & 250 & 3790 \\
3 & 19 & 6 & CSF & 118 & 725 \\
4 & 10 & 6 & Plasma & 790 & 1850 \\
\hline
\end{tabular}

Plasma and CSF samples were collected at the same time.

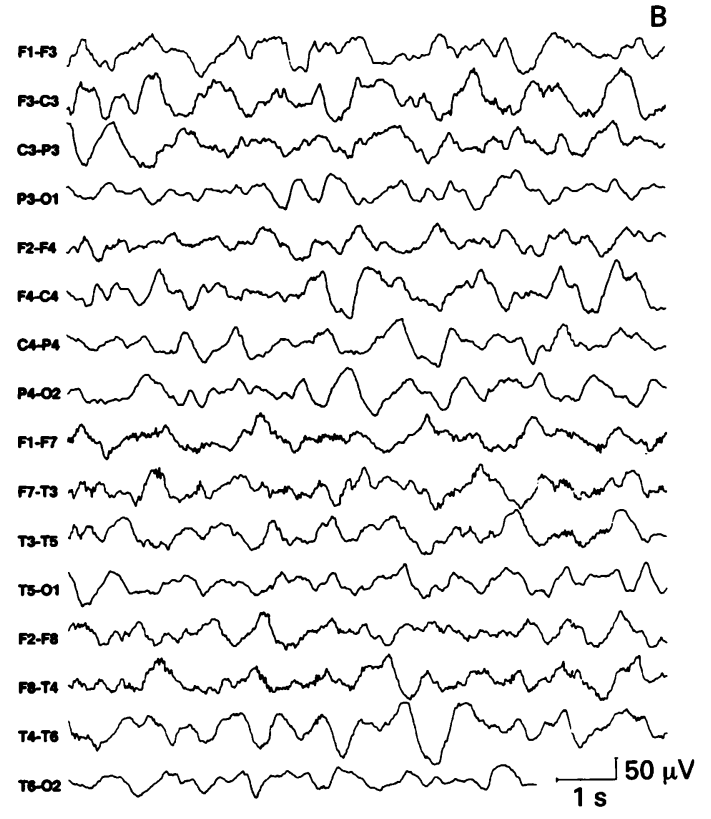

achieving an improvement. Side effects were not seen. On the other hand, a low dose $(\approx 5$ $\mathrm{mg} / \mathrm{kg} /$ day $)^{29}$ and a very low dose $(3 \times 7$ $\mathrm{mg} /$ day $)^{30}$ of dextromethorphan was effective. These doses, however, were ineffective in our patient with non-ketotic hyperglycinaemia, ${ }^{14}$ and in case 2 reduction to $22 \mathrm{mg} / \mathrm{kg} /$ day was followed by a relapse to seizures seven days later. On the other hand, $20 \mathrm{mg} / \mathrm{kg} /$ day dextromethorphan had an impressive effect on the EEG in case 3.

Post mortem investigations of case 2 revealed microbleeding in the region of the persisting low voltage epileptic discharges, obviously due to the overlying impression fracture of the skull. The resistance of these discharges to high doses of dextromethorphan ( $42 \mathrm{mg} / \mathrm{kg} / \mathrm{day}$ ) is consistent with the in vitro freeze lesion model of Troyer et al, ${ }^{31}$ in which interictal discharges were unaffected by NMDA antagonists.

\section{CONCENTRATION}

Inhibitory concentrations $\left(\mathrm{IC}_{50}\right)$ for reduction of NMDA-induced currents in voltage clamp experiments are $0.55 \mu \mathrm{M}$ for dextromethorphan and $0.096 \mu \mathrm{M}$ for dextrorphan. ${ }^{9} \mathrm{~A}$ concentration of $118 \mathrm{ng} / \mathrm{ml}$ dextromethorphan $(0.43 \mu \mathrm{M})$ and $725 \mathrm{ng} / \mathrm{ml}$ dextrorphan $(2.82$ $\mu \mathrm{M})$ in the CSF of case 3 may suffice for NMDA antagonism (table). Plasma concentrations of dextromethorphan were high in two patients, probably due to shock-induced hepatic failure (case 1), and to the short time interval (two hours) after treatment with dextromethorphan (case 2). The relation between the plasma concentrations and the therapeutic effects of dextromethorphan or dextrorphan could not be judged because (1) our preliminary data are too limited; (2) steady state levels were not reached; (3) dextrorphan possibly represents only a fraction of NMDA receptor active dextromethorphan metabolites; and (4) the efficacy of these 
metabolites might be different. Dextromethorphan, for example, seems to be nearly 10 times more potent in blocking NMDAinduced currents than dextromethorphan. ${ }^{9}$ The metabolism of dextromethorphan to dextrorphan or other compounds varies between patients ${ }^{32}$ and may be influenced by other drugs.

\section{CLINICAL OUTCOME}

The clinical outcome of our patients was disappointing. According to the post mortem examination in case 1, the initial EEG pattern in case 2 , the clinical course of the brother in case 3 , and the severe hypoglycaemia with long lasting refractory status epilepticus in case 4, no other outcome could be expected. Treatment with dextromethorphan was started several (2-14) days after the initial event-that is, probably too late to prevent NMDA-induced excitotoxicity.

The lack of effect on some convulsions was also disappointing. By contrast with our first case, ${ }^{14}$ myoclonic jerks in case 3 were unaffected by dextromethorphan, although contracortical spike wave complexes in the EEG disappeared. A side effect of dextromethorphan $^{19}$ could be excluded, because the myoclonic jerks occurred even before dextromethorphan was added. Although sharp and spike wave complexes had disappeared in case 4, tonic seizures and trismus persisted for several days.

\section{SIDE EFFECTS}

Dextromethorphan is an over the counter antitussive drug with a wide margin of safety and rare adverse reactions. ${ }^{33}$ The dose given to our patients, however, corresponds to a massive overdose for which side effects are sporadically reported (respiratory depression and various mental disturbances). ${ }^{33}$ Respiratory insufficiency was seen in two of our patients, but this could have been due to other causes. Nevertheless, a relation between high dose dextromethorphan and pneumonia cannot be excluded, as we also noted pneumonia in another (unpublished) patient treated with high dose dextromethorphan. On the other hand, our patient with non-ketotic hyperglycinaemia, ${ }^{14}$ now treated with high dose dextromethorphan for more than two years, has never had pulmonary problems.

Other reported side effects of dextromethorphan overdosing are somnolence, agitation, ${ }^{29}$ slurred speech, blurred vision, dizziness, vomiting, gait ataxia, nystagmus, and urinary retention. ${ }^{34}$ Naloxone seems to reverse the side effects of dextromethorphan, ${ }^{34}$ but obviously does not affect the NMDA receptor related anticonvulsant effects of its metabolite dextrorphan. ${ }^{16}$ Myoclonus, seen in animal models, ${ }^{19}$ has never been described in humans (see Bem and Peck $^{33}$ ). Side effects of NMDA receptor antagonists may be amplified in the presence of other antiepileptic drugs-for example, valproate. ${ }^{35}$

\section{OUTLOOK}

More experience and a proper study design are necessary to verify these preliminary data.
The decision to initiate treatment with dextromethorphan might have been too late for three of our patients. A future study design should consider an earlier introduction of dextromethorphan in patients with acute neurological diseases and epilepsy. In acute neurological diseases transient antagonism of the NMDA receptor may suffice to prevent brain damage by NMDA receptor mediated excitotoxicity. The blockade of NMDA receptors seems to be necessary until the overflow of excitatory amino acids is reduced or the reuptake system is stabilised. We assume that 10 days of high dose dextromethorphan and stepwise discontinuation over seven days would be an appropriate mode of treatment. Dextromethorphan should be discontinued or reduced before extubation is performed to avoid possible respiratory problems.

Long term administration of dextromethorphan is limited in childhood epilepsies, unless the underlying disease (non-ketotic hyperglycinaemia) requires a continuous NMDA receptor blockade. The supposed involvement of NMDA receptors in learning and memory processes suggests that long term treatment with NMDA antagonists is not desirable, especially in childhood.

As successful treatment with dextromethorphan is also limited by the unreliability of the oral route, intravenous treatment would have preference. Treatment with dextrorphan, the more potent compound at the NMDA receptor, might also overcome individual metabolic differences and improve reliability.

We are grateful to Mrs $\mathbf{M}$ Jonzier-Perey for skilful determination of the drug levels and to Dr SM Thompson (Brain Research Institute) and Dr G Richards (Hoffmann-LaRoche) for helpful comments on the manuscript.

1 Wong BY, Coulter DA, Choi DW, Prince DA. Dextrorphan and dextromethorphan, common antitussives, are antiepileptic and antagonize N-methyl-Daspartate in brain slices. Neurosci Lett 1988;85:261-6.

2 Aram JA, Martin D, Tomczyk M, Zeman S, Millar J, Pohler G, Lodge D. Neocortical epileptogenesis in vitro: studies with N-methyl-D-aspartate, phencyclidine, sigma and dextromethorphan receptor ligands. $f$ Pharmacol Exp Ther 1989;248:320-8.

3 Apland JP, Braitman DJ. Effects of non-opioid antitussives on epileptiform activity and NMDA responses in sives on epileptiform activity and NMDA responses in
hippocampal and olfactory cortex slices. Brain Res 1990;529:277-85.

4 Feeser HR, Kadis JL, Prince DA. Dextromethorphan, a common antitussive, reduces kindled amygdala seizures in the rat. Neurosci Lett 1988;86:340-5.

5 Ferkany JW, Borosky SA, Clissold DB, Pontecorvo MJ. Dextromethorphan inhibits NMDA-induced convulsions. Eur $\mathcal{F}$ Pharmacol 1988;151:151-4.

6 Chapman AG, Meldrum BS. Non-competitive N-methyl$D$-aspartate antagonists protect against sound-induced seizures in DBA/2 mice. Eur $\mathcal{f}$ Pharmacol 1989;166:201-11.

7 Church J, Lodge D, Berry SC. Differential effects of dextrorphan and levorphanol on the excitation of rat spinal neurons by amino acids. Eur $\mathcal{f}$ Pharmacol 1985;111: 185-90.

8 Netzer R, Pflimlin P, Trube G. Dextromethorphan blocks NMDA-induced currents and voltage-operated inward currents in cultured cortical neurons. Eur $¥$ Pharmacol currents in cultured

9 Netzer R, Graf V, Pflimlin P, Trube G. Effects of some NMDA receptor channel antagonists on voltagedependent $\mathrm{Ca}^{2+}$ channels in cultured cortical neurons. dependent $\mathrm{Ca}^{2+}$ channels in cultured cortical neurons. In: Krieglstein J, Oberpichler-Schwenk H, eds. Pharmacology of cerebral ischemia. Stuttga
Wissenschaftliche Verlagsgesellschaft, 1992:129-37.

10 Dingledine R, McBain CJ, McNamara JO. Excitatory amino acid receptors in epilepsy. Trends Pharmacol Sci 1990;11:334-8. 
11 Rogawski MA, Porter RJ. Antiepileptic drugs: pharmacological mechanisms and clinical efficacy with considera-
tion of promising developmental stage compounds. tion of promising developme

12 Kapur J, Lothman EW. NMDA receptor activation mediates the loss of GABAergic inhibition induced by recurrent seizures. Epilepsy Res 1990;5:103-11.

13 Stringer JL, Lothman EW. Use of maximal dentate activation to study the effect of drugs on kindling and kindled responses. Epilepsy Res 1990;6:180-6.

14 Schmitt B, Steinmann B, Gitzelmann R, ThunHohenstein L, Mascher H, Dumermuth G. Nonketotic hyperglycinemia: clinical and electrophysiological effects of dextromethorphan, an antagonist of the $\mathrm{N}$ methyl-D-aspartate (NMDA) receptor. Neuralogy 1993; methyl-D

15 Baumann P, Jonzier-Perey M. GC and GC-Ms procedures for simultaneous phenotyping with dextromethorphan and mephenytoin. Clin Chim Acta 1988;171: 211-22.

16 Tortella FC, Ferkany JW, Pontecorvo MJ. Anticonvulsant effects of dextrorphan in rats: possible involvement in dextromethorphan-induced seizure protection. Life $S_{c i}$ 1988;42:2509-14.

17 Tortella FC, Pellicano $M$, Bowery NG. Dextromethorphan and neuromodulation: old drug
coughs up new activities. Trends Pharmacol Sci 1989;10: 501-7.

18 Leander JD, Rathbun RC, Zimmerman DM. Anticonvulsant effects of phencyclidine-like drugs: relation to N-methyl-D-aspartic acid antagonism. Brain Res 1988;454:368-72.

19 Takazawa A, Anderson P, Abraham WC. Effects of dextromethorphan, a nonopioid antitussive, on developtromethorphan, a nonopioid antitussive, on develop-
ment and expression of amygdaloid kindled seizures. ment and expression of am

20 Rothman SM, Olney JW. Excitotoxicity and the NMDA receptor. Trends Neurosci 1987;10:299-302.

21 Monyer H, Choi DW. Morphinans attenuate cortical neuronal injury induced by glucose deprivation in vitro. Brain Res 1988;446:144-8.

22 McCulloch J, Bullock R, Teasdale GM. Excitatory amino acid antagonists: opportunities for the treatment of ischaemic brain damage in man. In: Meldrum BS, ed. Excitatory amino acid antagonists. Oxford: Blackwell Scientific Publications 1991:287-326.
23 Beal MF. Does impairment of energy metabolism result in excitotoxic neuronal death in neurodegenerative illnesses? Ann Neurol 1992;31:119-30.

24 Fariello RG, Golden GT, Smith GG, Reyes PF Potentiation of kainic acid epileptogenicity and sparing from neuronal damage by an NMDA receptor antagonist. Epilepsy Res 1989;3:206-13.

25 Clifford DB, Zorumski CF, Olney JW. Ketamine and MK-801 prevent degeneration of thalamic neurons induced by focal cortical seizures. Exp Neurol 1989; 105:272-9.

26 Straub H, Baker RE, Bingmann D, Speckmann EJ. Spontaneously appearing burst discharges in hippocampal and neocortical neurons (in vitro): suppression by the calcium antagonists verapamil and flunarizine [abstract]. Eur $\mathcal{F}$ Physiol 1991:418(suppl 1):43.

27 Meyer FB, Anderson RE, Sundt TM, Yaksh TL, Meyer FB, Anderson RE, Sundt TM, Yaksh TL,
Sharbrough FW. Suppression of pentylenetetrazole seizures by oral administration of a dihydropyridine $\mathrm{Ca}^{2+}$-antagonist. Epilepsia 1987;28:409-14.

28 Fisher RS, Cysyk BJ, Lesser RP, et al. Dextromethorphan for treatment of complex partial seizures. Neurology 1990;40:547-9.

29 Hamosh A, McDonald JW, Valle D, Francomano CA Niedermeyer E, Johnston MV. Dextromethorphan and high-dose benzoate therapy for nonketotic hyperglycinemia in an infant. $f$ Pediatr 1992;121:131-5.

30 Wieser HG, Beck H. Improvement of medically refractory temporal lobe epilepsy with dextromethorphan. $\mathcal{F}$ Epilepsy 1992;5:246-7.

31 Troyer MD, Blanton MG, Kriegstein AR. Abnormal action-potential bursts and synchronized, GABA-mediated inhibitory potentials in an in vitro model of focal ated inhibitory potentials in an in vi

32 Pfaff G, Briegel P, Lamprecht I. Inter-individual variation in the metabolism of dextromethorphan. Int $\mathcal{f}$ Pharmacol 1983;14:173-89.

33 Bem JL, Peck R. Dextromethorphan. An overview of safety issues. Drug Safety 1992;7:190-9.

34 Shaul WL, Wandell M, Robertson WO. Dextromethorphan toxicity: reversal by naloxone. Pediatrics 1977;59:117-9.

35 Hönack D, Dziki M, Löscher W. Effect of NMDA receptor antagonists on anticonvulsant activity and sideeffects of valproate [abstract]. Eur $\mathcal{f}$ Neurosci 1992; 5(suppl 1):2084. 